\title{
Morfodynamika sztucznie zasilonej plaży Baltyku pomiędzy Gdańskiem a Sopotem
}

\author{
Aleksandra Jobska ${ }^{1}$, Maria Rucińska ${ }^{1}$
}

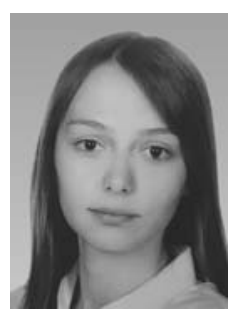

A. Jobska

Morphodynamics of the replenished Baltic beach between Gdańsk and Sopot. Prz. Geol., 69: 443-447; doi: $10.7306 / 2021.28$

A b s tract. The research area is located on the coast of the Baltic Sea, along the Gulf of Gdansk. It includes a beach where sand replenishment was carried out in 2019. The aim of the study was to investigate the morphodynamics of beach deposits in replenishing and non-replenishing areas during one year. No environmental dynamic conditions sufficient to alter significantly the beach morphology and sediment characteristics occurred during the study period, November 2019 to August 2020. One storm event was recorded, but did not significantly affect the beachform. The transverse beach profiles, which were artificially recharged in June 2019, were lowered by 0.6 to $1.2 \mathrm{~m}$. The greatest changes were caused by the erosive activity of the waters of the Jelitkowski Stream.

Keywords: Morphodynamics, beach replenishment, beach, beach sediment, the Gulf of Gdansk

$\mathrm{Na}$ odcinku wybrzeża południowego Bałtyku pomiędzy Gdańskiem a Sopotem natężenie procesów erozyjnych przeważa nad akumulacją osadów. Najistotniejszymi czynnikami erozyjnymi są $\mathrm{w}$ tej strefie wiatrowe falowanie wody, w tym głównie sztormowe, oraz wahania poziomu wody o dłuższych okresach, powodowane m.in. przez zmiany ciśnienia atmosferycznego (Furmańczyk, Musielak, 2005; Łabuz, 2020). Procesy erozyjne na plażach Gdańska oraz Sopotu sprawiają, że utrzymanie bezpieczeństwa przeciwpowodziowego wymaga powtarzalnego odtwarzania linii brzegowej. Prace refulacyjne, polegające na sztucznym zasilaniu plaż materiałem piaszczystym, są obecnie uznawane za metodę odbudowy brzegu morskiego najmniej ingerującą w środowisko przyrodnicze. W związku z tym metoda ta jest najczęściej stosowana do odbudowy pasa plażowo-wydmowego. Skład petrograficzny i granulacja osadu wykorzystywanego do refulacji powinny w jak największym stopniu przypominać naturalny osad występujący na terenie zasilanym (Łabuz, 2013).

W latach 2004-2007 administracja morska zrealizowała program ochrony brzegów morskich ze szczególnym wyróżnieniem sztucznego zasilania wybrzeża dzielnicy Jelitkowo w Gdańsku oraz wybrzeża Sopotu (Trzeciak i in., 2015). W 2007 r. na odcinek plaży w Gdańsku, łączący dzielnice Brzeźno i Jelitkowo, naniesiono 230 tys. $\mathrm{m}^{3}$ piasku, a w 2009 r. -70 tys. $\mathrm{m}^{3}$ (Łabuz, 2013).

W pierwszym kwartale 2019 r. Urząd Morski w Gdyni przeprowadził modernizację toru wodnego do Portu Północnego w Gdańsku - w ramach której poszerzono go do $600 \mathrm{~m}$ oraz pogłębiono do $18 \mathrm{~m}$ (Modernizacja..., 2019a). W czwartorzędowych, piaszczystych osadach wypełniających dno toru wydzielono trzy kompleksy piasków przydatnych do sztucznego zasilenia plaży pomiędzy Gdańskiem i Sopotem: kompleks górny - szarych piasków drobnoziarnistych, kompleks środkowy - piasków mulistych i iłów oraz kompleks dolny - szarych piasków średnioziarnistych. Część materiału piaszczystego stanowiły osady jeziorne oraz piaski z przewarstwieniami mułków, które uznano za nienadające się do refulacji (Trzeciak i in., 2015). Osad przeznaczony do refulacji przebadano pod kątem zawartości metali ciężkich, wielopierścieniowych węglowodorów aromatycznych (WWA) i polichlorowanych bifenyli (PCB). Stwierdzono, że zarówno stężenia wymienionych substancji chemicznych, jak i zawartość materii organicznej są w nich niewielkie (Trzeciak i in., 2015). Piasek ten przepompowano na plażę pomiędzy Gdańskiem a Sopotem za pomocą pływających rurociągów. W ten sposób dostarczono na nią aż $540126 \mathrm{~m}^{3}$ piasku (Modernizacja..., 2019b).

Celem badań opisanych w niniejszym artykule, prowadzonych w latach 2019-2020, było określenie zmian morfologii poprzecznych profili plaży Bałtyku na jej sztucznie zasilonym odcinku pomiędzy Gdańskiem i Sopotem, rozpoznanie sezonowej zmienności uziarnienia osadów plażowych, a także sprawdzenie, czy dotychczasowe prace refulacyjne spowodowały zmiany w uziarnieniu tych osadów.

\section{OBSZAR BADAŃ}

Badania prowadzono na wybrzeżu Zatoki Gdańskiej Morza Bałtyckiego (ryc. 1), na odcinku plaży od Sopotu na zachodzie po dzielnicę Gdańska Brzeźno na wschodzie. W rejonie Brzeźna holoceński, morski piasek plażowy występuje do głębokości $5 \mathrm{~m}$ p.p.t., poniżej są plejstoceńskie piaski wodnolodowcowe o miąższości do $10 \mathrm{~m}$ (Jegliński, 2013). Na tym odcinku wybrzeża wydmy usypane ze średnioziarnistego, holoceńskiego piasku eolicznego osiągają wysokość 5 m n.p.m. (Boniecka i in., 2013). Na północny zachód od Brzeźna miąższość holoceńskich piasków plażowych waha się od 2 do $5 \mathrm{~m}$. Pod nimi zalegają piaski żwirowe z drobnymi otoczakami, które stanowią bruk podstawowy serii transgresywnej. W rejonie Gdańska i Sopotu podatność strefy brzegowej na erozję jest większa niż w zachodniej części polskiego wybrzeża w okolicy Rowów i Kołobrzegu (Mojski, 1979).

Na wybrzeżu południowego Bałtyku wiatr wieje przeważnie z południa, południowego zachodu i zachodu. Średnia roczna prędkość wiatru wynosi $3,4 \mathrm{~m} / \mathrm{s}$. Jesienią i zimą osiąga on największą prędkość, średnio $7 \mathrm{~m} / \mathrm{s}$. Wiatr sztormowy, którego prędkość przekracza $11 \mathrm{~m} / \mathrm{s}$, jest rejestrowany kilkadziesiąt razy $\mathrm{w}$ ciągu roku. Najmniejszą

\footnotetext{
${ }^{1}$ Wydział Oceanografii i Geografii, Uniwersytet Gdański, al. Marszałka Piłsudskiego 46, 81-378 Gdynia; aleksandra.jobska@gmail.com
} 


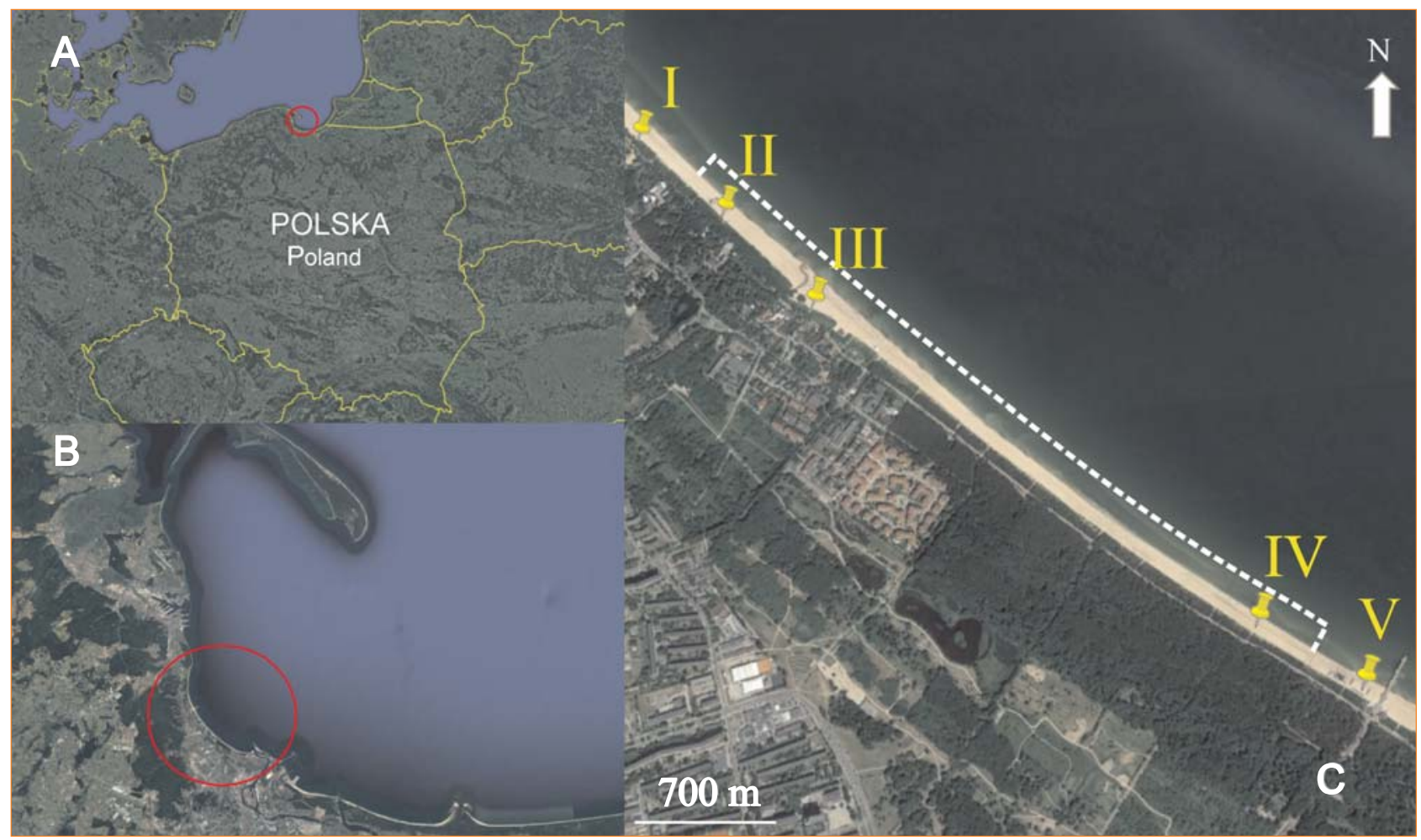

Ryc. 1A-C. Lokalizacja obszaru badań. Pinezkami oznaczono usytuowanie profili pomiarowych: I - Sopot, II - Jelitkowo po lewej stronie od Potoku Jelitkowskiego, III - Jelitkowo po prawej stronie od Potoku Jelitkowskiego, IV - Brzeźno, V - Brzeźno molo; linią przerywaną zaznaczono obszar refulowany. Źródło: Google Earth Pro

Fig. 1A-C. Location map of the research area. Measurement profiles are marked with pins: I - Sopot, II - Jelitkowo, on the left side of the Jelitkowski Stream, III - Jelitkowo, on the right side of the Jelitkowski Stream, IV - Brzeźno, V-Brzeźno pier; the dashed line marks the replenished area. Source: Google Earth Pro

prędkość wiatru $(2,5$ do $4 \mathrm{~m} / \mathrm{s})$ obserwuje się od maja do września. Wiatr oraz zmiany ciśnienia atmosferycznego przyczyniają się do wahania poziomu morza. Najniższy poziom morza jest obserwowany podczas wiatru z południa oraz południowego zachodu, natomiast najwyższy podczas silnych, długotrwałych wiatrów północnych. W strefie brzegowej Gdańska przeważają małe fale o wysokości do $2 \mathrm{~m}$ (Trzeciak i in., 2015). Normalny poziom wody w Zatoce Gdańskiej wynosi $500 \mathrm{~cm}$, w czasie wezbrań sztormowych podnosi się on średnio do $570 \mathrm{~cm}$. W latach 1960-2010 odnotowano w Gdańsku 253 spiętrzenia sztormowe. Najwyższy poziom morza zarejestrowano w listopadzie 2004 r. - $644 \mathrm{~cm}$ oraz październiku 2009 r. $-620 \mathrm{~cm}$ (Przygrodzki, Letkiewicz, 2015).

\section{METODYKA}

W listopadzie 2019 r., lutym, maju oraz sierpniu 2020 r. wzdłuż pięciu profili poprzecznych plaż Gdańska i Sopotu (ryc. 1) pobrano do badań sedymentologicznych łącznie 85 próbek osadów powierzchniowych. Trzy profile badawcze wyznaczono na plaży poddanej refulacji w 2019 r. Są to: profile II i III - Gdańsk Jelitkowo oraz profil IV - Gdańsk Brzeźno (ryc. 1). Dwa profile wyznaczono na sąsiadujących odcinkach plaż niepoddanych sztucznemu zasilaniu: profil I - Sopot i profil V - Gdańsk Brzeźno molo (ryc. 1). Za pomocą urządzenia GPS RTK firmy Leica Geosystems GS08/CS10, które niezależnie od chwilowego poziomu morza ukazuje stały poziom odniesienia i umożliwia wykonanie pomiarów z dokładnością do $1 \mathrm{~cm}$, w każdym sezonie badawczym sporządzano profile poprzeczne plaży w wymienionych pięciu lokalizacjach. Na podstawie danych lidarowych, uzyskanych w ramach monitoringu brzegu morskiego (Monitoring..., 2018), porównano profile poprzeczne plaży w Gdańsku Jelitkowie po prawej stronie od Potoku Jelitkowskiego (profil III) oraz Gdańsku Brzeźnie (profil IV) przed refulacją w 2019 r. i po jej wykonaniu.

Próbki osadów powierzchniowych pobierano (z głębokości od 0 do $0,05 \mathrm{~m}$ p.p.t.) z górnej części plaży, wału brzegowego, czoła plaży oraz stopnia kipielowego, a także z miejsc, w których zauważono zmiany cech osadu. Wszystkie próbki osadów wysuszono w suszarce laboratoryjnej w temperaturze $105^{\circ} \mathrm{C}$ do stałej masy i poddano je analizie granulometrycznej zgodnie z instrukcją Myślińskiej (2006). Osad przesiewano przez zestawy sit o wielkości oczek: 4,0;2,8;2,0;1,4;1,0;0,71;0,5;0,355;0,25; 0,$18 ; 0,125 ; 0,09$ i $0,063 \mathrm{~mm}$. Do opracowania wyników wykorzystano program Gradistat (Blott, Pye, 2001), który umożliwia obliczenie takich wskaźników statystycznych jak: średnia średnica, odchylenie standardowe oraz skośność. Statystyczne wskaźniki uziarnienia obliczono metodą Folka i Warda (1957).

\section{WYNIKI}

Na plaży Bałtyku pomiędzy Gdańskiem i Sopotem występuje piasek średnioziarnisty. W okresie badań w rejonie Sopotu (profil I) średnia średnica ziaren powierzchniowego osadu plaży mieściła się w przedziale od 1,27 $\phi$ (listopad 2019 r.) do 1,59 ф (sierpień 2020 r.). Najmniejszą średnicę ziaren odnotowano w lutym 2020 r. (0,55 ф), a największą w listopadzie 2019 r. (2,01 ф). Na plaży Gdańska po lewej stronie Potoku Jelitkowskiego (profil II) występował 
piasek o średniej średnicy od 1,55 $\phi$ (luty 2020 r.) do 1,98 $\phi$ (listopad 2019 r.). Największą średnią średnicę ziaren stwierdzono w listopadzie 2019 r. $(2,26 \phi)$, natomiast najmniejszą w lutym 2020 r. $(0,87 \phi)$. Na plaży po prawej stronie Potoku Jelitkowskiego (profil III) występował piasek o średniej średnicy ziaren od 1,71 do 1,99 $\phi$. Największą średnicę ziaren odnotowano w maju 2020 r. (2,33 $\phi)$, a najmniejszą w listopadzie 2019 r. (0,85 ф). Średnia średnica ziaren piasku pobranego z plaży Brzeźna (profil IV) mieściła się w zakresie od 1,70 do 1,77 $\phi$. Minimalną i maksymalną średnią średnicę ziaren piasku odnotowano $\mathrm{W}$ listopadzie 2019 r. $(0,39 \phi$ i 2,16 $\phi)$. Na całym obszarze badań najmniejszą średnią średnicę ziaren miał piasek pochodzący ze stopnia kipielowego, który wyznacza strefe rozmywania osadów powierzchniowych (Racinowski i in., 2001).

Średnie wysortowanie osadów powierzchniowych na plaży w Sopocie - nieobjętej refulacją - mieściło się w przedziale $0,54-0,59 \phi$, natomiast wysortowanie osadów plaż Jelitkowa i Brzeźna, które poddano refulacji, w granicach $0,55-0,65 \phi$ (ryc. $2 A)$. Zatem na całym obszarze badań osad powierzchniowy był umiarkowanie dobrze wysortowany.

Na plażach gdańskich dzielnic Jelitkowo oraz Brzeźno skośność osadu była prawie symetryczna (ryc. 2B) - mieściła się w przedziale od $-0,09 \phi$ (maj 2020 r.) do 0,05 $\phi$ (luty 2020 r.). Średnia skośność piasku na plaży w Sopocie (nierefulowanej) mieściła się w zakresie od -0,12 $\phi$ (maj 2020 r.) do 0,17 申 (luty 2020 r.). W listopadzie 2019 r. oraz sierpniu 2020 r. osad odznaczał się prawie symetryczną skośnością.

W górnej i środkowej części poprzecznego profilu plaży w Sopocie występował dobrze wysortowany piasek średnioziarnisty o prawie symetrycznej skośności. W listopadzie 2019 r. w dolnej części plaży odnotowano umiarkowanie wysortowany piasek średnioziarnisty o skośności negatywnej, natomiast w sierpniu 2020 r. umiarkowanie dobrze wysortowany piasek średnioziarnisty o skośności pozytywnej. W listopadzie 2019 r. na górnej części plaży w Gdańsku Jelitkowie występował umiarkowanie dobrze wysortowany piasek średnioziarnisty o skośności negatywnej. W sierpniu 2020 r. na całej szerokości plaży odnotowano umiarkowanie dobrze wysortowany piasek średnioziarnisty o prawie symetrycznej skośności.

Poprzeczne profile plaży, na skutek oddziaływania procesów erozyjno-akumulacyjnych, uległy w trakcie badań nieznacznym przekształceniom. W listopadzie 2019 r. odnotowano najkrótsze profile, natomiast w sierpniu $2020 \mathrm{r}$. najdłuższe. Plaża w Sopocie charakteryzowała się profilem wklęsło-wypukłym, z wyraźnie widocznym wałem brzegowym, utrzymującym się przez cały okres badań. Profil plaży Jelitkowa (II) był wypukły.

W lutym 2020 r. wystąpił sztorm, podczas którego poziom morza przekroczył stan ostrzegawczy $(550 \mathrm{~cm})$. Wyraźne ślady maksymalnego napływu sztormowego, w postaci nagromadzeń detrytusu organicznego, były widoczne w środkowej części plaży. Na poprzecznym profilu plaży w Sopocie, wykonanym dzień po sztormie, gdy poziom morza wynosił $511 \mathrm{~cm}$, wyraźnie zaznaczyło się zwiększenie szerokości wału brzegowego i przesunięcie jego krawędzi w stronę morza (ryc. 3). Na poprzecznym profilu plaży Jelitkowa, wykonanym po tym samym sztormie, zaobserwowano znaczne obniżenie poziomu plaży w środkowej i dolnej części profilu (ryc. 3).

Na plaży Jelitkowa znajduje się ujście Potoku Jelitkowskiego. W listopadzie 2019 r. koryto tego potoku znajdowało się w odległości kilku metrów na północny zachód od profilu numer III (ryc. 1), jednak w lutym 2020 r. przesunęło się na południowy wschód i przecięło linię tego profilu. W listopadzie 2019 r. (sześć miesięcy po refulacji) długość poprzecznego profilu plaży po prawej stronie Potoku Jelitkowskiego wynosiła 95 m (ryc. 3). Po sztormie w lutym 2020 r. szerokość plaży zmniejszyła się do 75-80 m,

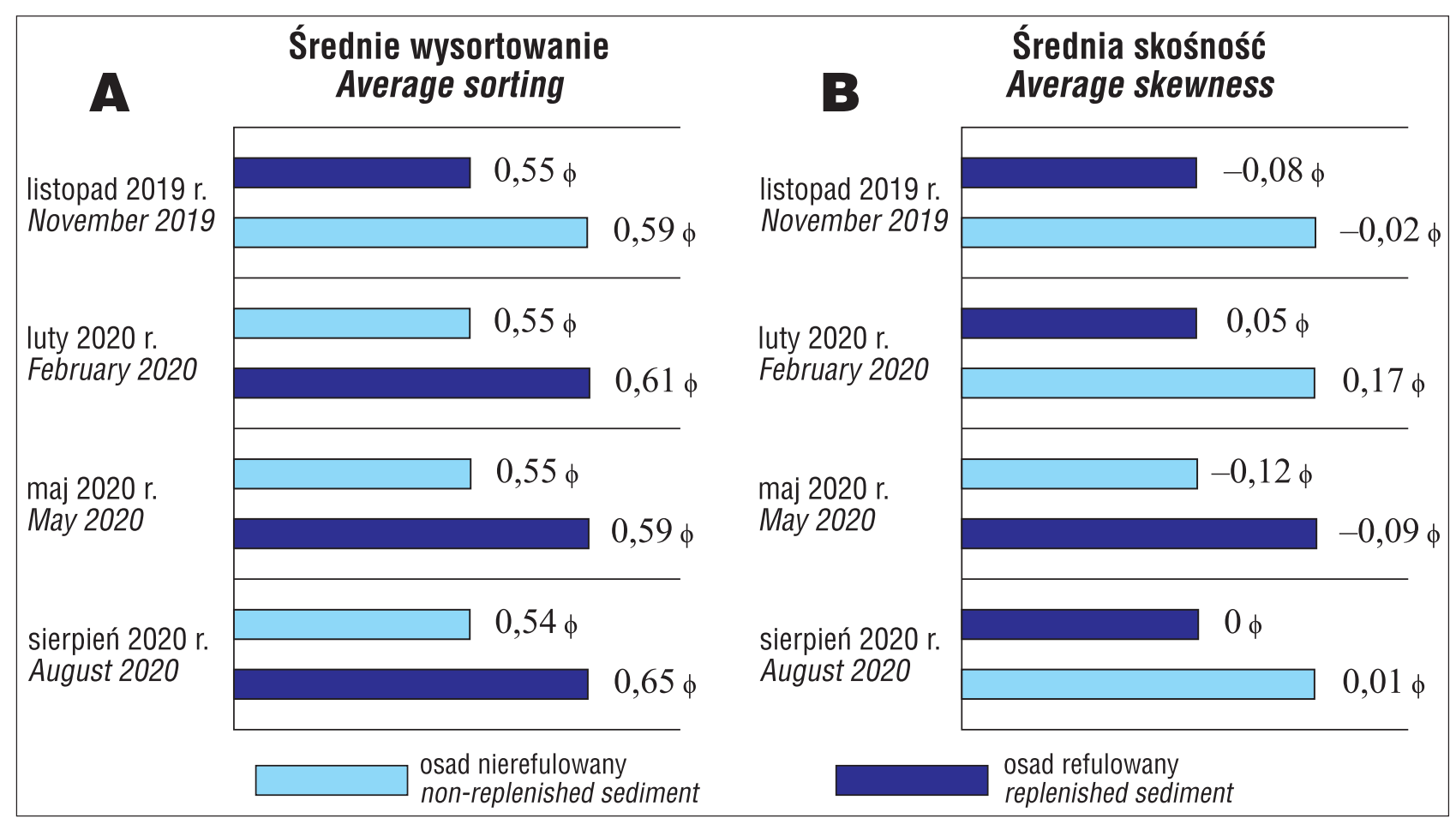

Ryc. 2. Sezonowe zmiany średniego wysortowania (A) i średniej skośności (B) osadu refulowanego i nierefulowanego Fig. 2. Seasonal changes in average sorting (A) and average skewness (B) of replenished and non-replenished sediment 


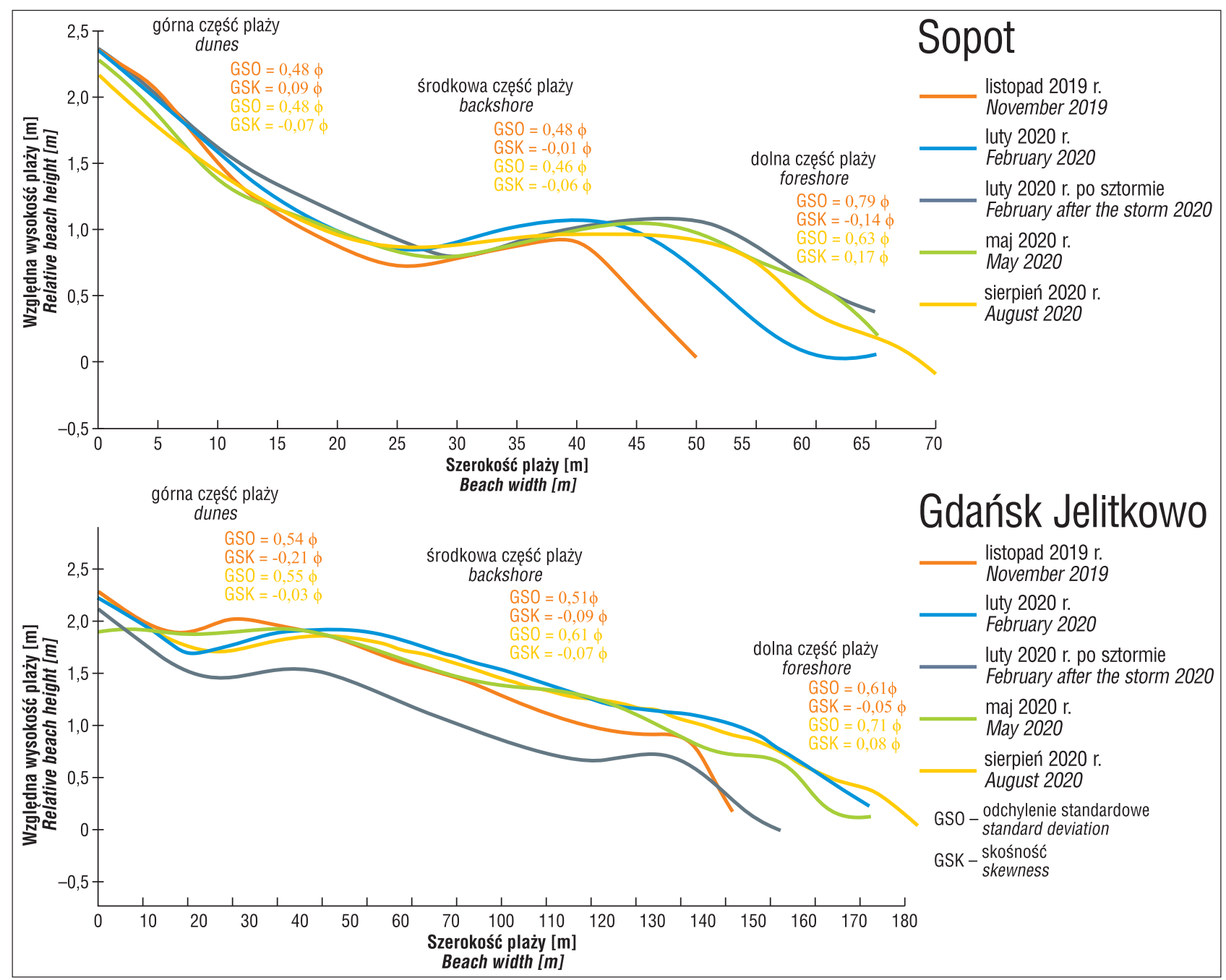

Ryc. 3. Zmiany poprzecznych profili plaży i statystycznych wskaźników uziarnienia osadu na plaży refulowanej (Gdańsk Jelitkowo) i nierefulowanej (Sopot)

Fig. 3. Changes in transverse beach profiles and statistical indices of sediment grain size on a replenished (Gdańsk Jelitkowo) and non-replenished (Sopot) beach

jednak kształt profilu nie uległ zmianie. W maju 2020 r. poprzeczny profil plaży Jelitkowa (III) kończył się na brzegu koryta Potoku Jelitkowskiego. Między majem a sierpniem 2020 r. koryto Potoku Jelitkowskiego ponownie wycofało się na północny zachód od profilu III. W sierpniu 2020 r. poprzeczny profil plaży Jelitkowa miał szerokość $105 \mathrm{~m}$ i ponownie zaznaczał się w nim wał brzegowy. Profil ten odzwierciedla kształt plaży po wycofaniu się Potoku Jelitkowskiego.

\section{PODSUMOWANIE I WNIOSKI}

Plaża Jelitkowa (profil III) w listopadzie 2019 r. była o $40 \mathrm{~m}$ szersza od plaży przed refulacją wykonaną w pierwszej połowie 2019 r., a jej powierzchnia wznosiła się wyżej o 1,8 m. Utrzymywał się wyrównany, wypukły, poprzeczny profil plaży (Monitoring..., 2018), jaki wytworzono w trakcie prac refulacyjnych w celu łagodnego wygaszania fal sztormowych, a tym samym ochrony brzegu morskiego przed erozją (Trzeciak i in., 2015). Od listopada 2019 r. do sierpnia 2020 r. profil górnej części plaży Jelitkowa obniżył się o 0,6 m, a dolnej o 1,2 m. Jednak nie zmniejszyła się jej szerokość. Do tak znacznego obniżenia terenu przyczyniła się również erozyjna działalność Potoku Jelitkowskiego.

Plaża Brzeźna (profil IV) w listopadzie 2019 r. była o $37 \mathrm{~m}$ szersza i wznosiła się o $2 \mathrm{~m}$ wyżej niż przed refulacją. Od listopada 2019 r. do sierpnia 2020 r. jej poziom obniżył się o $1 \mathrm{~m}$. W zbliżonym czasie w rejonie Kołobrzegu odnotowano obniżenie plaży o $0,1 \mathrm{~m} \mathrm{w}$ ciagu sześciu miesięcy, natomiast w Rowach o 0,25 m (Hojan i in., 2019). Wynika z tego wniosek, że w rejonie Gdańska i Sopotu podatność strefy brzegowej na erozjęjest większa niż w zachodniej części polskiego wybrzeża.

Od listopada 2019 r. do sierpnia 2020 r. nie wystapiły warunki dynamiczne środowiska, wystarczające do istotnej zmiany morfologii plaży i cech jej osadu. W czasie badań odnotowano wystąpienie jednego sztormu, który przekroczył stan ostrzegawczy poziomu morza $(550 \mathrm{~cm})$, jednak na obszarze objętym refulacją w 2019 r. nie zarejestrowano znaczących zmian morfologicznych plaży po sztormie. Jedynie na terenie nierefulowanym (Sopot) odnotowano wydłużenie wału brzegowego w stronę morza. Poprzeczne profile plaż, które sztucznie zasilono w pierwszej połowie 2019 r., obniżyły się o 0,6 do 1,2 m. Za obniżenie profilu Jelitkowa (III) w dużej mierze odpowiada erozyjna działalność wód Potoku Jelitkowskiego. 
Średnia średnica ziaren oraz barwa powierzchniowego osadu na plaży refulowanej były podobne do osadu na plaży nie objętej refulacją (ryc. 2). Spełnione zostały zatem założenia dotyczące cech refulatu, który powinien przypominać wielkością ziaren oraz barwą osad naturalnie odkładany przez morze (Łabuz, 2013). W osadzie powierzchniowym pobranym na plaży Sopotu stwierdzono sezonowy wzrost średniej średnicy ziaren w skali Krumbeina $\phi$, który wskazuje na zmniejszenie energii środowiska na badanym obszarze.

Autorki serdecznie dziękują Anonimowemu Recenzentowi za krytyczne uwagi, które przyczyniły się do gruntownego poprawienia treści artykułu.

\section{LITERATURA}

BLOTT S.J., PYE K. 2001 - Gradistat: a grain size distribution and statistics package for the analysis of unconsolidated sediments. Uk Surface Processes and Modern Environm. Res. Group: 1241-1242.

BONIECKA H. (red.) 2013 - Monitoring i badania dotyczace aktualnego stanu brzegu morskiego - ocena skuteczności systemów ochrony brzegu morskiego zrealizowanych w okresie obowiązywania wieloletniego Programu ochrony brzegów morskich. Inst. Morski, Gdańsk: 71-139.

FURMAŃCZYK K., MUSIELAK S. 2005 -ZZOP w Polsce - stan obecny perspektywy. Problemy erozji brzegu. Oficyna In Puls, Szczecin: 55-60.

FOLK R.L., WARD W.C. 1957 - Brazos River bar, a study of significance of grain size parameters. J. Sed. Petrol., 27: 3-26.

Google Earth Pro - https://www.google.pl/intl/pl/earth/download/gep/agree.html

HOJAN M., RUREK M., KRUPA A. 2019 - The Impact of Sea Shore Protection on Aeolian Processes using the Example of the Beach in Rowy, N Poland. Geosciences, 9: 179.
JEGLIŃSKI W. 2013 - Rozwój wybrzeża Zatoki Gdańskiej w rejonie ujścia Wisły Martwej. Prz. Geol., 61: 587-595.

ŁABUZ T.A. 2013 - Sposoby ochrony brzegów morskich i ich wpływ na środowisko przyrodnicze polskiego wybrzeża Bałtyku. WWF: 83-98.

ŁABUZ T.A. 2020 - Wpływ spiętrzeń sztormowych na erozję plaż i ich sztuczne zasilanie w Łebie. Inżynieria Morska i Geotechnika. Wyd. IMOGEOR Sp. z o.o., Gdańsk: 63.

MOJSKI J.E. 1979 - Objaśnienia do szczegółowej mapy geologicznej Polski, ark.Gdańsk (27) w skali 1:50 000, gm. Gdańsk, pow. gdański, woj. pomorskie. Wyd. Geol., Warszawa: 42-45.

MODERNIZACJA toru wodnego do Portu Północnego w Gdańsku. Urząd Morski w Gdyni, 2019a; www.umgdy.gov.pl/?p=9158

MODERNIZACJA toru wodnego do Portu Północnego w Gdańsku. Urząd Morski w Gdyni, 2019b; https://www.umgdy.gov.pl/wp-content/uploads/2019/12/Prezentacja-dot.-realizacji.pdf

MONITORING brzegu morskiego na podstawie danych uzyskanych metodą lotniczego skanowania laserowego oraz ortofotomapy (edycja 2018) - OPEGIEKA, Elbląg, 2018.

MYŚLIŃSKA E. 2006 - Laboratoryjne badania gruntów. Wyd. UW, Warszawa.

PRZYGRODZKI P., LETKIEWICZ B. 2015 - Charakterystyka wezbrań sztormowych wzdłuż polskiego wybrzeża Morza Bałtyckiego. Inż. Mor. Geotech., 3: 158-165.

RACINOWSKI R., SZCZYPEK T., WACH J. 2001 - Prezentacja i interpretacja wyników badań uziarnienia osadów czwartorzędowych. Wyd. US, Katowice: 100-105.

TRZECIAK A., BRODZICKA P., CHOJNACKA M., ELŻANOWSKA M., FABRYKIEWICZ R., KACZMARCZYK-GUZIK A., MAZUREK-HAJ-

DUK M. 2015 - Rozbudowa toru podejściowego z powiększeniem jego szerokości i głębokości technicznej wraz z wykonaniem obrotnicy o średnicy $750 \mathrm{~m}$. Raport o oddziaływaniu na środowisko. Arch. Transprojekt Gdański Sp. z o.o.; https://www.umgdy.gov.pl/wp-content/uploads/2015/09/FE_POIS_TWPP_ROS.pdf

Praca wpłynęła do redakcji 8.04.2021 r

Akceptowano do druku 18.06.2021 r. 